\title{
The Experience With Health Care of Patients With Inflammatory Arthritis
}

\section{A Cross-sectional Survey Using the Instrument to Evaluate the Experience of Patients With Chronic Diseases}

\author{
Javier de Toro, PhD, * Luis Cea-Calvo, MD,† María L. García-Vivar, MD, $\ddagger$ Lucía Pantoja, MD, $\S$ \\ Cristina Lerin-Lozano, MD,// Silvia García-Díaz, BSc, ף María J. Galindo, PhD,\# \\ Ignacio Marín-Jiménez, MD, ** Sabela Fernández, BPharm, PhD, $\dagger$ \\ Yvonne Mestre, BPharm, $\uparrow$ and Domingo Orozco-Beltrán, PhD ††
}

\begin{abstract}
Background: Patients' experience with health care is becoming a key component for the provision of a patient-centered health care model. The aim of this study was to assess the experience with health care of patients with inflammatory arthritis and patient- and health care-related factors.

Methods: Patients responded to an anonymous survey provided by their treating clinical teams. The survey comprised the validated 12-item IEXPAC (Instrument to Evaluate the EXperience of PAtients with Chronic diseases) tool and demographic variables and health care-related characteristics that may affect patients' experience.

Results: A total of 359 of 625 surveys were returned (response rate, $57.4 \%)$. Overall, patient responses were positive $(>60 \%$ gave "always/ mostly" answers) for statements assessing the interaction between patients and health care professionals or patient self-management following health care professional guidance. However, positive patient responses for items regarding patient interaction with the health care system via the internet or with other patients were less than $13 \%$. Only $25.6 \%$ of patients who had been hospitalized reported receiving a follow-up call or visit following discharge. In the bivariate analysis, experience scores were higher (better experience) in men, those seen by fewer specialists or by the same physician, and in patients treated with a fewer number of drugs or with subcutaneous/intravenous drugs. Multivariate analyses identified regular follow-up by the same physician and treatment with subcutaneous/intravenous drugs as variables associated with a better patient experience.
\end{abstract}

From the *Rheumatology Department, Hospital Universitario A Coruña, Universidade da Coruña, INIBIC, A Coruña; †Medical Affairs, Merck Sharp \& Dohme Spain, Madrid; †Rheumatology Department, Basurto University Hospital, Bilbao; §Hospital El Bierzo, Ponferrada; „Rheumatology Department, Manacor Hospital, Mallorca; $\uparrow$ Rheumatology Department, Hospital Transversal Sant Joan Despí Moisès Broggi-General, Consorci Sanitari Integral, Barcelona; \#Internal Medicine Department, Hospital Clínico de Valencia; **Gastroenterology Department, Hospital Universitario Gregorio Marañón, Madrid; and $+\dagger$ Department of Medicine, Miguel Hernández University, Sant Joan, Alicante, Spain.

This study was funded by Merck Sharp \& Dohme Spain, a subsidiary of Merck \& Co., Inc., Kenilworth, NJ.

L.C.-C., S.F., and Y.M. are full-time employees at Merck Sharp \& Dohme Spain. M.L.G.-V. is a consultant to Janssen, Novartis, Bristol, Sanofi, and Celgene; provides expert testimony for Celgene, Novartis, AbbVie, and Pfizer; and receives payments for lectures from Janssen, UCB, AbbVie, Celgene, Novartis, Pfizer, and Lilly; meeting expenses from Pfizer, Sanofi, Lilly, and AbbVie; grants (to her institution) from Janssen and UCB. L.P. is a consultant to UCB and receives payment for lectures from Gebro Pharma, MSD, and Roche. M.J.G. is a consultant to Gilead and Janssen and receives payments for lectures or educational presentations from Gilead, Janssen, MSD, and AbbVie and grant from Janssen. I.M.-J. is a board member of or consultant to AbbVie, Chiesi, FAES Farma, Falk-Pharma, Ferring, Gebro Pharma, Hospira, Janssen, MSD, Otsuka Pharmaceutical, Pfizer, Shire, Takeda, Tillots, and UCB Pharma; and receives payments for lectures from AbbVie, Chiesi, FAES Farma, Falk-Pharma, Ferring, Gebro Pharma, Hospira, Janssen, MSD, Otsuka Pharmaceutical, Pfizer, Shire, Takeda, Tillots, and UCB Pharma. D.O.-B. is a consultant to MSD, Sanofi, Novo
Conclusions: This study identifies areas of care for patients with inflammatory arthritis with the potential to improve patients' experience and highlights the importance of patient-physician relationships and comprehensive patient care.

Key Words: chronic disease, patient experience, patient survey, rheumatic disease

(J Clin Rheumatol 2021;27: 25-30)

D atients' experience with health care is a key component for the provision of a patient-centered health care model, as both clinical effectiveness and patients' safety are correlated positively with patients' experience. ${ }^{1}$ In patients with chronic conditions, a more positive patient experience is associated with improved quality of care, ${ }^{2}$ with the interaction of patients with health care professionals, particularly general practitioners, being important for patient wellbeing. ${ }^{3}$ Effective chronic illness management also depends on multidisciplinary care teams, including nurses and pharmacists, with clinical and behavioral skills. ${ }^{4}$

Rheumatic diseases affect a significant proportion of the population and are a major cause of disability worldwide, adversely affecting quality of life and causing lost productivity and increased health care costs. ${ }^{5,6}$ We have reported previously the outcomes of a

Nordisk, Mundipharma, and Menarini. The other authors declare no conflict of interest.

The following patients' association participated in the design of the overall study and endorsed it: Spanish Association of Patients with Arthritis (CONARTRITIS); Spanish Association of Patients with Crohn's Disease and Ulcerative Colitis (ACCU); and the Spanish Federation of Patients with Diabetes (FEDE), and by the Spanish AIDS Multidisciplinary Society (SEISIDA). Editorial support was provided by David P. Figgitt, $\mathrm{PhD}$, ISMPP CMPP, and Robert A. Furlong, PhD, Content Ed Net, with funding from MSD Spain.

Author Contributions: J.d.T., L.C.-C., M.J.G., I.M.-J., and D.O.-B. designed the study and coordinated the implementation. L.C.-C. and J.d.T. drafted the manuscript. The other authors made substantial contributions to the manuscript. All authors reviewed and approved the final version.

Correspondence: Luis Cea-Calvo, MD, Medical Affairs Department, Merck Sharp \& Dohme Spain, Josefa Valcárcel 38, 28027 Madrid, Spain. E-mail: luis.cea@merck.com.

Supplemental digital content is available for this article. Direct URL citation appears in the printed text and is provided in the HTML and PDF versions of this article on the journal's Web site (www.jclinrheum.com).

Copyright (C) 2019 The Author(s). Published by Wolters Kluwer Health, Inc. This is an open-access article distributed under the terms of the Creative Commons Attribution-Non Commercial-No Derivatives License 4.0 (CCBY-NC-ND), where it is permissible to download and share the work provided it is properly cited. The work cannot be changed in any way or used commercially without permission from the journal.

ISSN: $1076-1608$

DOI: $10.1097 /$ RHU.0000000000001155 
survey to assess the experience of patients with 4 different chronic conditions (i.e., inflammatory arthritis, inflammatory bowel disease [IBD], human immunodeficiency virus [HIV] infection, and diabetes mellitus) with health care using the Instrument to Evaluate the EXperience of PAtients with Chronic diseases (IEXPAC) tool. ${ }^{7}$ IEXPAC is a validated questionnaire developed in Spain with several advantages over other available questionnaires (namely, a focus on the overall interaction of patients with the health care system and not with specific professionals and the inclusion of a broader notion of integrated care, including social care, patients' self-management, new technological interventions, and patients' interactions with other patients). ${ }^{8}$ In the previously mentioned study, ${ }^{7}$ patients with HIV infection described better experience with health care than patients with other chronic diseases. Because approaches to patients' care can differ based on patient-specific chronic conditions, we deemed it of interest to perform an analysis of specific patient profiles. In this work, we focus on the cohort of patients with inflammatory arthritis, with the objective of describing patient perceptions of health care, identifying the main areas for improvement, and assessing potential variables affecting patient experience (including demographic variables and health carerelated characteristics).

\section{METHODS}

This was a cross-sectional survey of patients with chronic conditions, and the present substudy focuses on the subset of patients with inflammatory arthritis. This subgroup was constituted of patients older than 18 years with rheumatoid arthritis, axial spondyloarthritis, or psoriatic arthritis, receiving health care in rheumatology clinics from 25 participating hospital clinics across Spain. Twenty-five consecutive patients attending each clinic were handed a survey by their clinical teams, which included the IEXPAC questionnaire as its focus, and they were instructed to voluntarily complete and return it from home by prepaid post mail. This patient cohort was part of a larger study of 4 chronic diseases comprising inflammatory arthritis, diabetes mellitus, IBD, and HIV infection. The study protocol, methodology, and main outcomes for the overall population have been described elsewhere. ${ }^{7}$ The protocol, instructions for patients, and survey content were reviewed and approved by the Clinical Research Ethic Committee of the Gregorio Marañón Hospital of Madrid, Spain. Because of the anonymous nature of the survey, and as agreed by the Clinical Investigation Ethics Committee, the voluntary return of completed surveys was taken as patient implied consent to participate in the survey. There was no collection of data from the patients' medical records.

\section{Survey Instrument}

The survey included the IEXPAC questionnaire mainly, plus additional multiple-choice questions providing information on patient demographics, and health care- and treatment-related characteristics. The survey was drafted by expert physicians with the input of patients with the aforementioned chronic conditions and was endorsed by the Spanish Association of Patients with Arthritis (CONARTRITIS) and other patients' associations. ${ }^{7}$ The entire survey is provided as supplementary material (Supplemental Digital Content 1, http://links.lww.com/RHU/A159).

Details of the IEXPAC questionnaire have been published. ${ }^{8}$ Briefly, IEXPAC is a 12-item questionnaire with patient responses made using a 5-point Likert scale ranging from "always" (score 10) to "never" (0). An overall score is given by summing the scores of items 1 to 11 and dividing by 11 , which describe patient experience within the last 6 months. Item 12, describing hospitalization in the last 3 years, is reported separately. Three factors are derived from IEXPAC items 1 to 11 . Factor 1 (productive interactions) refers to the content and characteristics of interactions between patients and health care professionals and is the mean score of items 1,2 , 5 , and 9. Factor 2 (new relational model) refers to new forms of patient interaction with the health care system through the internet or with peers and is the mean score of items 3, 7, and 11. Factor 3 (patient self-management) is the ability of individuals to manage their own care and improve their well-being based on health care professional-mediated interventions and is the mean score of items $4,6,8$, and 10 .

\section{Statistical Analysis}

This is an exploratory study with no formal hypothesis or prespecified sample size. A conservative approach was adopted to calculate each cohort sample size based on a qualitative variable with an expected prevalence of $50 \%, 95 \%$ confidence interval, and with $6 \%$ precision. This approach gave an initial calculated sample size of 267 patients, plus $15 \%$ of variables completed incorrectly (314 patients), and accounting for an expected response rate of approximately $50 \%$, as found in other surveys handed to patients by clinical teams, ${ }^{9,10}$ to give a total sample size of 628 patients with rheumatic diseases.

Descriptive information is displayed as mean and SD for quantitative variables, and frequencies or percentages for qualitative variables. The results of the IEXPAC questionnaire were calculated as overall mean (SD) score and mean (SD) scores for factors 1 to 3 . The distribution of responses to each item is also displayed, as well as the mean score for each item.

The $x^{2}$ or the Fisher exact tests were used for comparison of proportions, and the Student $t$ test or analysis of variance used to compare continuous variables. Multiple linear regression models were used to assess different demographic and health care-related variables influencing the IEXPAC overall score and individual factor scores. Given the overall descriptive nature of the results, no multiplicity adjustments were made, and there was no imputation for missing data.

\section{RESULTS}

\section{Description of the Sample}

Surveys were distributed and collected between May and September 2017. A total of 359 of 625 surveys handed out to patients with inflammatory arthritis were returned (response rate, $57.4 \%$ ). Patients' demographic and health care-related characteristics are presented in Table 1. The mean (SD) age of respondents was 54.6 (13.9) years; $63.3 \%$ were women. Only $6.2 \%$ were affiliated to a patient's association, and $67.7 \%$ searched for information about health care from sources different from those provided by health care providers. For $7.9 \%$ of patients, follow-up for health care required visiting a Spanish region different from their residing region. The mean (SD) number of different specialists visited in the past year was $4.3(2.6)$, with primary care physicians $(81.6 \%)$ visiting most frequently. Patient follow-up was commonly performed by the same physician ( $84.9 \%$ of patients), whereas for nearly half of patients (49.0\%), follow-up was also done by a nurse. Support from non-health care workers (relatives or friends, caregiver) for health care was received by $46.8 \%$ of patients. The mean (SD) number of medicines taken daily was 4.4 (2.6), and $58.5 \%$ of patients received subcutaneous (SC) or intravenous (IV) medications. The proportion of patients hospitalized within the past 3 years was $41.2 \%$.

\section{IEXPAC Responses and Experience Scores}

The distribution of patients' responses to the 12 IEXPAC items and the mean score of each item are shown in Table 2. The proportion of patients who responded "always" or "mostly" to items related to factors 1 (productive interactions score) and 3 
TABLE 1. Patient Demographics and Health Care-Related Characteristics of Patients Who Completed the Survey $(n=359)$

\begin{tabular}{|c|c|}
\hline Parameter & Value \\
\hline \multicolumn{2}{|l|}{ Patient demographics } \\
\hline Age, mean (SD), y & $54.6(13.9$ \\
\hline Sex, women, $\%$ & 63.3 \\
\hline \multicolumn{2}{|l|}{ Educational level achieved } \\
\hline Primary, \% & 43.8 \\
\hline Secondary, including vocational, $\%$ & 32.5 \\
\hline University or further, \% & 23.6 \\
\hline $\begin{array}{l}\text { Barthel Index of Activities of Daily Living, } \\
\text { Barthel } \leq 80, \%\end{array}$ & 13.2 \\
\hline Affiliated to patients' association, $\%$ & 6.2 \\
\hline $\begin{array}{l}\text { Searched for information about health care from } \\
\text { sources different from health care providers } \\
\text { (i.e., internet, media, etc.), \% }\end{array}$ & 67.7 \\
\hline \multicolumn{2}{|l|}{ Health care-related characteristics } \\
\hline $\begin{array}{l}\text { Follow-up for health care in a Spanish region } \\
\text { different from the patient's main residence, \% }\end{array}$ & 7.9 \\
\hline $\begin{array}{l}\text { No. of different specialists (including primary } \\
\text { care) visited in the past year, mean (SD) }\end{array}$ & $4.3(2.6)$ \\
\hline $1-2$ specialists, $\%$ & 24.0 \\
\hline 3-4 specialists, $\%$ & 36.8 \\
\hline$\geq 5$ specialists, $\%$ & 39.2 \\
\hline \multicolumn{2}{|l|}{$\begin{array}{l}\text { Patient follow-up is usually done by the } \\
\text { same physician? }\end{array}$} \\
\hline Generally, the same physician, \% & 84.9 \\
\hline Sometimes different, $\%$ & 11.2 \\
\hline Frequently different, \% & 3.9 \\
\hline Follow-up by a nurse, $\%$ & 49.0 \\
\hline $\begin{array}{l}\text { Support from others (relatives or friends, } \\
\text { caregiver) for health care, } \%\end{array}$ & 46.8 \\
\hline \multicolumn{2}{|l|}{ Treatment-related characteristics } \\
\hline No. medicines taken daily, mean (SD) & $4.4(2.6)$ \\
\hline 0-2 medicines, $\%$ & 26.3 \\
\hline 3-4 medicines, $\%$ & 34.3 \\
\hline$\geq 5$ medicines, $\%$ & 39.4 \\
\hline Treated with SC or IV medications, $\%$ & 58.5 \\
\hline Hospitalization within the past $3 \mathrm{y}, \%$ & 41.2 \\
\hline
\end{tabular}

${ }^{\text {a }}$ Specialists visited most frequently were primary care physician $(81.6 \%)$, ophthalmologist $(32.9 \%)$, dermatologist $(24.8 \%)$, gynecologist $(24.2 \%)$, and orthopedic surgeon (22.3\%).

(self-management score) were greater than $60 \%$, except for item 10 (informed on the health and social resources, 33.8\%). Factor 2 (new relational model) items showed a low proportion of "always/mostly" responses $(<13 \%)$. Only $25.6 \%$ of patients who had been hospitalized in the past 3 years reported to have received a follow-up call or visit after discharge.

The mean (SD) overall IEXPAC score was 5.5 (2.0). Mean (SD) scores were higher for factors 1 (productive interactions score, 7.5 [2.5]) and 3 (self-management score, 6.5 [2.5]) than for factor 2 (new relational model: 1.7 [2.1]). IEXPAC experience scores stratified by different demographic and health care-related variables are shown in Supplemental Digital Content 2, http://links.lww.com/ RHU/A160, and a summary of the bivariate analysis is shown in Table 3. Men had slightly higher overall score $(p=0.022)$ and higher scores for factors 1 (productive interactions, $p=0.013$ ) and 3 (patient self-management, $p=0.024$ ). Productive interactions and selfmanagement factor scores were higher in aged patients ( $p$ linear trend $=0.033$ and 0.041 , respectively). New relational model factor (factor 2) scores were higher in patients with higher educational level ( $p$ linear trend $=0.028$ ).

With regard to health care characteristics, patients followed up in a region different from their home region scored higher in the overall score $(p=0.004)$ and in the new relational model $(p<0.001)$ and self-management $(p=0.048)$ factors. Overall score and productive interactions and self-management factor scores were higher in patients seen by a smaller number of specialists ( $p$ linear trend $=0.025$, 0.017 , and 0.040 , respectively) and in those followed up by the same physician compared with follow-up by different physicians ( $p<0.001$ in all cases). Scores were similar for patients who had follow-up by a nurse compared with no nurse follow-up.

Finally, the overall experience score and the productive interactions score were higher in patients treated with a lower number of drugs ( $p$ linear trend $=0.039$ and 0.005 , respectively) and in those treated with SC or IV drugs, but these failed to reach statistical significance ( $p=0.083$ and 0.099 , respectively).

\section{Multivariate Analysis}

Results of multiple linear regression analyses are shown in Table 4. Factors associated with higher overall IEXPAC score (indicating a better experience) were being followed regularly by the same physician $(p=0.001)$ and received treatment with SC or IV drugs $(p=0.021)$. These variables were also associated with better productive interactions ( $p<0.001$ and $p=0.013$, respectively) and self-management ( $p<0.001$ and 0.040 , respectively) scores. Associations between a lower number of specialists and higher IEXPAC scores, or between male gender and higher factor 1 score, did not reach statistical significance by multivariate analysis.

\section{DISCUSSION}

This study describes the health care experience of adult patients with inflammatory arthritis (rheumatoid arthritis, axial spondyloarthritis, or psoriatic arthritis) using the IEXPAC questionnaire, ${ }^{8}$ identifying not only positive aspects of patient experience but also areas for improvement. Overall, patient responses were much more positive for factors 1 (productive interactions) and 3 (self-management) than for the new relational model factor. Most patients $(>60 \%)$ provided positive responses ("always/ mostly") for 7 of the 8 items in factors 1 and 3 . The exception was item 10 (patient information on health and social resources), where only a third of patients gave positive responses. This is in broad agreement with an Italian study of patients with rheumatic diseases where only $37 \%$ were satisfied with the information provided during treatment. ${ }^{11}$

Positive patient responses for the 3 items in the new relational model factor were less than $13 \%$. The low percentage of patients who responded "always/mostly" to the statement "They help me to get information from the internet" identifies a clear area of improvement given that, in this study, two-thirds of these patients declared searching information in sources different to health care providers. In addition, approximately only a quarter of patients who had been hospitalized reported having received a follow-up call or visit following discharge, but more than $40 \%$ had been hospitalized in the past 3 years. Thus, there seems to be a need for more proactive communication from health care professionals to patients after discharge from hospitalization.

In an analysis of the overall study population, ${ }^{7}$ only $6.1 \%$ of patients reported being affiliated with a patient's association; similarly, in the current subgroup of patients with inflammatory arthritis, only $6.2 \%$ of patients were affiliated with a patient's association. Affiliation with patients' associations has not been frequent in the past in Spain, but it is increasing as communication channels are more 
TABLE 2. Patient Responses (\%) and Mean Scores for Each IEXPAC Item

\section{IEXPAC Item}

\section{They respect my lifestyle}

The professionals who care of me listen to me and ask me about my needs, habits, and preferences to adapt my treatment and care plan.

2. They are coordinated to offer good health care to me

Health and social care services are coordinated to improve my well-being and quality of life in my environment (family, neighborhood, town).

3. They help me to get information from the internet

The professionals who care for me inform me about trustful web pages and internet forums that I can consult to know my disease better, its treatment, and the consequences they may have on my life.

4. Now I can take care of myself better

I feel that my confidence in my ability to take care of myself, manage my health problems, and keep my autonomy has improved.

5. They ask me and help me to follow my treatment plan

I regularly review adherence to my treatment and care plan with the professionals who care for me.

6. We set goals for a healthy life and better control my illness

I've been able to agree with the professionals who care for me on specific objectives regarding diet, physical exercise, and medication to get better control of my health problems.

7. I can use the internet and my mobile phone to consult my medical records I can consult my clinical record, tests results, programmed visits, and access to other services through the internet or the mobile app of my health service.

8. They make sure that I take medication correctly

The professionals who care for me review with me all of the medication I take, how I take it, and how it suits me.

9. They worry about my welfare

The professionals who care for me are concerned with my quality of life, and I feel they are committed to my well-being,

10. I have been informed on health and social resources that can help me

The professionals who care for me inform me about health and social resources available in my neighborhood or town that I can use to improve my health problems and take better care of myself.

11. They encourage me to talk to other patients

The professionals who care for me invite me to participate in patient groups to share information and experiences on how to care for ourselves and improve our health.

Respond to the following statement only if you have been admitted to the hospital in the last $3 \mathrm{y}$

12. They care about me when I come home after being in the hospital

After hospital discharge, they have called or visited me at home to see how I was and what care I needed.

\begin{tabular}{|c|c|c|c|c|c|}
\hline \multicolumn{5}{|c|}{ Patient Responses (\%) } & \multirow{2}{*}{$\begin{array}{c}\text { Mean } \\
\text { Score (SD) }\end{array}$} \\
\hline Always & Mostly & Sometimes & Seldom & Never & \\
\hline 49.3 & 27.2 & 15.8 & 5.2 & 2.6 & $7.9(2.6)$ \\
\hline 37.0 & 23.6 & 15.8 & 7.5 & 16.1 & $6.4(3.6)$ \\
\hline 5.5 & 7.1 & 12.8 & 15.1 & 59.3 & $2.1(3.1)$ \\
\hline 41.5 & 32.8 & 21.5 & 1.8 & 2.4 & $7.7(2.4)$ \\
\hline 53.3 & 20.2 & 14.0 & 6.8 & 5.7 & $7.7(3.0)$ \\
\hline 41.4 & 22.0 & 15.2 & 7.7 & 13.7 & $6.7(3.6)$ \\
\hline 4.0 & 3.3 & 5.5 & 7.3 & 79.9 & $1.1(2.5)$ \\
\hline 54.6 & 17.8 & 7.7 & 6.2 & 13.6 & $7.3(3.6)$ \\
\hline 60.3 & 18.8 & 13.4 & 3.0 & 4.5 & $8.1(2.7)$ \\
\hline 21.1 & 12.7 & 14.8 & 13.6 & 37.8 & $4.1(4.0)$ \\
\hline 6.1 & 4.2 & 13.9 & 12.4 & 63.3 & $1.9(3.0)$ \\
\hline 18.2 & 7.4 & 8.8 & 6.1 & 59.5 & $3.0(4.0)$ \\
\hline
\end{tabular}

"Productive interactions" factor: items 1, 2, 5, and 9; "new relational model" factor: items 3, 7, and 11; "patient self-management" factor: items 4, 6, 8, and 10.

accessible and patients perceive the benefits of being affiliated. Clearly, the higher the proportion of patients who are affiliated with patients' associations, the more likely it is that patient-patient communication will be facilitated, increasing the opportunities for productive interactions with other patients. This highlights the importance of implementing actions (e.g., educating patients about the activities and advantages of patients' associations) to establish productive communication with other patients, starting with good physician-patient communication. ${ }^{12-14}$

Both bivariate and multivariate analyses identified that regular follow-up by the same physician was associated with a better patient experience. This demonstrates the importance of building good patient-physician relationships, which may aid communication. Interestingly, there was no association between follow-up by nurses and a better patient experience. In contrast, in the cohort of IBD patients, follow-up by nurses was associated with a better patient experience. ${ }^{15}$ This difference may be due to nurse specialization in IBD clinics. Rheumatic patients in the current study were recruited from general hospital rheumatology clinics, which deal with more clinically diverse diseases, where nurses are not necessarily specialized in inflammatory arthritis. However, a better experience was identified for rheumatic disease patients treated with SC/IV drugs, which may be due to more personalized care, involving not only physicians but also pharmacists and nurses, and easier access to their clinical teams. Therefore, the role of nurses is very relevant, at least in this subset of patients treated with SC/IV drugs, in which nurses have a role in training patients in the use of devices, preparing them for IV infusions, or in the follow-up of drug tolerability or adherence. In another survey, patients with rheumatic diseases who were receiving SC biological therapy reported high treatment satisfaction, but also reported that the clinical teams failed to address personal problems derived from their 
TABLE 3. Bivariate Analysis: Variables Associated With Better Experience Scores (See Supplementary Table 1 for Additional Information)

\begin{tabular}{|c|c|c|c|c|}
\hline Parameter & $\begin{array}{l}\text { Overall IEXPAC } \\
\text { Experience Score }\end{array}$ & $\begin{array}{l}\text { Productive Interactions } \\
\text { Score (Factor 1) }\end{array}$ & $\begin{array}{c}\text { New Relational } \\
\text { Model Score (Factor 2) }\end{array}$ & $\begin{array}{l}\text { Patient Self-management } \\
\text { Score (Factor 3) }\end{array}$ \\
\hline Age & - & Older $^{\mathrm{a}}$ & - & Older $^{\mathrm{a}}$ \\
\hline Gender & Men & Men & - & Men \\
\hline Educational level achieved & - & Lower ${ }^{\mathrm{a}, \mathrm{b}}$ & Higher $^{\mathrm{a}}$ & - \\
\hline Barthel Index $>80$ & - & - & - & - \\
\hline $\begin{array}{l}\text { Follow-up in a region different from } \\
\text { home region (vs. same region) }\end{array}$ & Different & - & Different & Different \\
\hline No. specialists visited in the past year & Lower $^{\mathrm{a}}$ & Lower $^{\mathrm{a}}$ & - & Lower $^{\mathrm{a}}$ \\
\hline $\begin{array}{l}\text { Follow-up by the same physician } \\
\text { (vs. different) }\end{array}$ & Same physician & Same physician & - & Same physician \\
\hline $\begin{array}{l}\text { Follow-up by a nurse (vs. no nurse } \\
\text { follow-up) }\end{array}$ & - & - & - & - \\
\hline $\begin{array}{l}\text { Having help from others for health } \\
\text { care (vs. self-care only) }\end{array}$ & - & - & - & - \\
\hline No. different medicines taken & Lower $^{\mathrm{a}}$ & Lower $^{\mathrm{a}}$ & - & - \\
\hline $\begin{array}{l}\text { Being treated with } \mathrm{SC} / \mathrm{IV} \text { drugs } \\
\text { (vs. no SC/IV treatment) }\end{array}$ & - & - & - & - \\
\hline
\end{tabular}

The table displays the values of the variables associated with better experience scores in the bivariate analysis $(p<0.05)$.

${ }^{\mathrm{a}}$ Denotes a linear trend.

${ }^{\mathrm{b}} p=0.055$.

rheumatic diseases. ${ }^{10}$ Findings from these studies suggest the importance of a holistic approach, focusing not solely on the disease but on the patient as a person, to improve his/her experience with health care.

We have previously described the limitations of this study. ${ }^{7}$ Because anonymous surveys preclude characterization of the nonrespondent population, we cannot rule out a certain selection bias to patients with better experience with their health care, who could have been more likely to respond. For the present cohort, we selected patients with rheumatoid arthritis, axial spondyloarthritis, or psoriatic arthritis to ensure we covered a proportion of patients receiving SC/IV drugs, likely to receive different care from those receiving only oral drugs. However, patients did not identify their rheumatic condition in the survey, and consequently, we cannot draw conclusions for specific diseases or for patients with other rheumatic diseases such as vasculitis or connective tissue diseases. Finally, the

TABLE 4. Multivariate Analysis: Multiple Logistic Regression Analyses for the Overall IEXPAC Experience Score and for Factors 1 to 3

\begin{tabular}{|c|c|c|c|c|c|c|c|c|}
\hline \multirow[b]{2}{*}{ Parameter } & \multicolumn{2}{|c|}{$\begin{array}{c}\text { Overall IEXPAC } \\
\text { Experience Score }\end{array}$} & \multicolumn{2}{|c|}{$\begin{array}{c}\text { Productive } \\
\text { Interactions (Factor 1) } \\
\end{array}$} & \multicolumn{2}{|c|}{$\begin{array}{c}\text { New Relational } \\
\text { Model (Factor 2) }\end{array}$} & \multicolumn{2}{|c|}{$\begin{array}{c}\text { Patient Self-management } \\
\text { (Factor 3) }\end{array}$} \\
\hline & $\begin{array}{l}\beta \text { Coefficient } \\
\text { (SD) }\end{array}$ & $p$ value & $\begin{array}{l}\beta \text { Coefficient } \\
\text { (SD) }\end{array}$ & $p$ value & $\begin{array}{l}\beta \text { Coefficient } \\
\text { (SD) }\end{array}$ & $p$ value & $\begin{array}{l}\beta \text { Coefficient } \\
\text { (SD) }\end{array}$ & $p$ value \\
\hline Sex (women vs. men) & $-0.43(0.28)$ & 0.132 & $-0.65(0.36)$ & 0.073 & $-0.13(0.30)$ & 0.663 & $-0.46(0.35)$ & 0.189 \\
\hline Age (per year of increment) & $0.00(0.01)$ & 0.715 & $0.01(0.01)$ & 0.682 & $-0.00(0.01)$ & 0.886 & $0.01(0.01)$ & 0.659 \\
\hline $\begin{array}{l}\text { Educational level achieved } \\
\text { (university or further) }\end{array}$ & $-0.02(0.19)$ & 0.933 & $-0.28(0.24)$ & 0.251 & $0.32(0.20)$ & 0.112 & $-0.03(0.23)$ & 0.886 \\
\hline $\begin{array}{l}\text { Follow-up in a region different } \\
\text { from home region (vs. same region) }\end{array}$ & $0.62(0.54)$ & 0.252 & $0.09(0.68)$ & 0.896 & $1.11(0.57)$ & 0.053 & $0.78(0.67)$ & 0.243 \\
\hline Barthel Index $>80$ & $0.28(0.37)$ & 0.451 & $0.26(0.47)$ & 0.578 & $0.48(0.39)$ & 0.226 & $0.27(0.46)$ & 0.554 \\
\hline $\begin{array}{l}\text { No. specialists visited in the last year } \\
\text { (per unit of increment) }\end{array}$ & $-0.12(0.07)$ & 0.080 & $-0.14(0.08)$ & 0.082 & $-0.05(0.07)$ & 0.447 & $-0.12(0.08)$ & 0.122 \\
\hline $\begin{array}{l}\text { Follow-up by the same physician } \\
\text { (vs. different) }\end{array}$ & $0.84(0.26)$ & 0.001 & $1.17(0.33)$ & $<0.001$ & $0.08(0.27)$ & 0.773 & $1.15(0.32)$ & $<0.001$ \\
\hline $\begin{array}{l}\text { Follow-up by a nurse (vs. no nurse } \\
\text { follow-up) }\end{array}$ & $0.10(0.29)$ & 0.738 & $-0.08(0.37)$ & 0.822 & $0.43(0.31)$ & 0.167 & $-0.04(0.36)$ & 0.914 \\
\hline $\begin{array}{l}\text { Having help from others for health } \\
\text { care (vs. only self-care) }\end{array}$ & $0.30(0.30)$ & 0.308 & $0.09(0.38)$ & 0.809 & $0.42(0.32)$ & 0.189 & $0.49(0.36)$ & 0.178 \\
\hline $\begin{array}{l}\text { No. different medicines (per unit } \\
\text { of increment) }\end{array}$ & $-0.03(0.06)$ & 0.580 & $-0.05(0.07)$ & 0.454 & $0.01(0.06)$ & 0.927 & $0.00(0.07)$ & 0.958 \\
\hline $\begin{array}{l}\text { Being treated with SC/IV drugs } \\
\text { (vs. no SC/IV treatment) }\end{array}$ & $0.64(0.27)$ & 0.021 & $0.87(0.35)$ & 0.013 & $0.32(0.29)$ & 0.275 & $0.69(0.33)$ & 0.040 \\
\hline
\end{tabular}

Positive coefficients indicate higher IEXPAC experience scores. 
current sample represents a balanced distribution of the population of the different regions of Spain, but the sample size is not powered to detect differences among regions; this would require a much larger sample size.

In conclusion, this study has identified areas of rheumatic disease care with potential to improve patients' experiences if properly addressed, such as patient interaction with the health care system via the internet or with peers, provision of patient information on health and social resources, and closer follow-up after hospital discharge. The study also highlights the importance of patient-physician relationships and a comprehensive multidisciplinary approach.

\section{KEY POINTS}

- Using the validated 12-item IEXPAC tool, we assessed the experience with health care of patients with inflammatory arthritis.

- Overall, patient responses were positive regarding the interaction between patients and health care professionals or patient selfmanagement following health care professional guidance, but not for patient interaction with the health care system via the internet or with other patients and for follow-up after hospital discharge.

- Being followed up by the same physician and treatment with $\mathrm{SC} / \mathrm{IV}$ drugs were associated with better patients' experience with health care.

- Our study highlights the importance of patient-physician relationships and comprehensive patient care and identifies areas of care for patients with inflammatory arthritis with the potential to improve patient experience.

\section{ACKNOWLEDGMENTS}

The authors thank all patients who completed the survey and the IEXPAC working group for providing such a valuable tool.

\section{REFERENCES}

1. Doyle C, Lennox L, Bell D. A systematic review of evidence on the links between patient experience and clinical safety and effectiveness. BMJ Open. 2013;3:e01570.

2. Cramm JM, Nieboer AP. High-quality chronic care delivery improves experiences of chronically ill patients receiving care. Int J Qual Health Care. 2013;25:689-695.
3. Cramm JM, Nieboer AP. The importance of productive patient-professiona interaction for the well-being of chronically ill patients. Qual Life Res. 2015;24:897-903.

4. Wagner EH. The role of patient care teams in chronic disease management BMJ. 2000;320:569-572.

5. Sangha O. Epidemiology of rheumatic diseases. Rheumatology (Oxford). 2000;39(suppl 2):3-12.

6. Carmona L, Ballina J, Gabriel R, et al. The burden of musculoskeletal diseases in the general population of Spain: results from a national survey. Ann Rheum Dis. 2000;60:1040-1045.

7. Orozco-Beltrán D, de Toro J, Galindo MJ, et al. Healthcare experience and their relationship with demographic, disease and healthcare-related variables: a cross-sectional survey of patients with chronic diseases using the IEXPAC scale. Patient. 2019;12:307-317.

8. Mira JJ, Nuño-Solinís R, Guilabert-Mora M, et al. Development and validation of an instrument for assessing patient experience of chronic illness care. Int J Integr Care. 2016;16:13.

9. Bos-Touwen I, Schuurmans M, Monninkhof EM, et al. Patient and disease characteristics associated with activation for self-management in patients with diabetes, chronic obstructive pulmonary disease, chronic heart failure and chronic renal disease: a cross-sectional survey study. PLoS One. 2015; 10:e0126400.

10. González CM, Carmona L, de Toro J, et al. Perceptions of patients with rheumatic diseases on the impact on daily life and satisfaction with their medications: RHEU-LIFE, a survey to patients treated with subcutaneous biological products. Patient Prefer Adherence. 2017;11:1243-1252.

11. Giacomelli R, Gorla R, Trotta F, et al. Quality of life and unmet needs in patients with inflammatory arthropathies: results from the multicentre, observational RAPSODIA study. Rheumatology (Oxford). 2015;54: 792-797.

12. Ha JF, Longnecker N. Doctor-patient communication: a review. Ochsner J. 2010;10:38-43.

13. Verlinde E, de Laender N, de Maesschalck S, et al. The social gradient in doctor-patient communication. Int J Equity Health. 2012;11:12.

14. Warnecke E. The art of communication. Aust Fam Physician. 2014;43: 156-158.

15. Marín-Jiménez J, Casellas F, Cortés X, et al. The experience of inflammatory bowel disease patients with healthcare: a survey with the IEXPAC instrument. Medicine. 2019;98:e15044.

\begin{tabular}{|c|c|c|c|c|c|c|c|c|c|c|c|c|c|c|c|c|}
\hline & & & & & & & & & & & & & $\mathrm{N}$ & $\mathrm{N}$ & & \\
\hline & & & & & & 5 & & & & & & & $\forall$ & y & & \\
\hline & & $\perp$ & & & & $\bar{O}$ & & & & & & $\nabla$ & 1 & ก & & \\
\hline & & & & $\Xi$ & & & $\forall$ & & $\mathbf{V}$ & & & 0 & $\exists$ & & $S$ & \\
\hline & & & & & & $S$ & & $S$ & 10 & ] & & 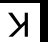 & & & & \\
\hline & & & & & & 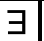 & $S$ & & $y$ & & & & I & $\mathrm{s}$ & $\exists$ & \\
\hline & & 0 & & & $\exists$ & 1 & $\lambda$ & $\mathrm{H}$ & $d$ & 0 & $S$ & $\exists$ & $\mathrm{H}$ & $\perp$ & $\mathrm{N}$ & \\
\hline & & & & & 0 & & $\forall$ & S & & & & $\exists$ & $\perp$ & $\cap$ & $\forall$ & \\
\hline & & $S$ & $\mathrm{O}$ & $\mathrm{N}$ & $I$ & כ & 7 & $\forall$ & 0 & 0 & y & 0 & $\mathrm{~N}$ & 0 & $\mathrm{H}$ & \\
\hline & & C & & & & & & $y$ & $\exists$ & $\Lambda$ & $\exists$ & & $\forall$ & $\perp$ & $\perp$ & \\
\hline & & cy & $\bar{H}$ & & $\lambda$ & $S$ & $\forall$ & $\perp$ & $\mathrm{N}$ & $\forall$ & $\exists$ & & 0 & $\mathrm{~N}$ & $\exists$ & \\
\hline & 3 & $\exists$ & & & & $\exists$ & $\mathbf{N}$ & & 0 & $S$ & & & $\forall$ & $\exists$ & $y$ & \\
\hline & & & & & & 7 & I & & & & & y & & & & \\
\hline & $\perp$ & ᄉ & $\mathrm{H}$ & $d$ & & $\exists$ & $\perp$ & $S$ & 0 & & 0 & $\cap$ & $S$ & & & \\
\hline & & y & & & & כ & $\mathbf{N}$ & 1 & כ & & & $\mathrm{H}$ & y & $\exists$ & $\wedge$ & \\
\hline & $\exists$ & $\exists$ & $\mathrm{N}$ & & & $\mathrm{N}$ & 0 & $y$ & $\forall$ & 5 & & $S$ & $\exists$ & $\mathrm{N}$ & $\exists$ & 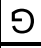 \\
\hline & & & & & & & $\exists 1$ & & & & & & $\mathrm{H}$ & & & \\
\hline
\end{tabular}

